\title{
The expression profile of $m i R$-3099 during neural development of Ts1Cje mouse model of Down syndrome
}

Shahidee Zainal Abidin ${ }^{1}$, Han-Chung Lee ${ }^{2,3}$, Syahril Abdullah ${ }^{2,3}$, Norshariza Nordin ${ }^{2,3}$, Pike-See Cheah ${ }^{3,4}$ and King-Hwa Ling 2,3,*

\footnotetext{
${ }^{1}$ Biological Security and Sustainability (BIOSES) Research Interest Group \& Eco-Innovation Research Interest Group, Faculty of Science and Marine Environment, Universiti Malaysia Terengganu, Terengganu, Malaysia

${ }^{2}$ Department of Biomedical Sciences, Faculty of Medicine and Health Sciences, Universiti Putra Malaysia, Selangor, Malaysia

${ }^{3}$ Genetics and Regenerative Medicine Research Group, Faculty of Medicine and Health Sciences, Universiti Putra Malaysia, Selangor, Malaysia

${ }^{4}$ Department of Human Anatomy, Faculty of Medicine and Health Sciences, Universiti Putra Malaysia, Selangor, Malaysia

* Correspondence: Ikh@upm.edu.my; Tel.: +603 97692564
}

Received: 5 November 2020; Accepted: 31 January 2021; Published: 15 March 2021

Edited by: Noraishah Mydin Abdul Aziz (Universiti Malaya, Malaysia)

Reviewed by: Meow-Keong Thong (Universiti Malaya, Malaysia); Azlina Ahmad Annuar (Universiti Malaya, Malaysia); Wael Mohamed (Menoufia Medical School Shebin El Kom, Egypt)

https://doi.org/10.31117/neuroscirn.v4i1.62

\begin{abstract}
MicroRNA-3099 (miR-3099) plays a crucial role in regulating neuronal differentiation and development of the central nervous system (CNS). The miR-3099 is a pro-neuronal miRNA that promotes neural stem/progenitor cell (NSPC) differentiation into neuronal lineage by suppressing astrogliogenesis. Down syndrome (DS) brain exhibited increased astrogliogenesis and reduced neuronal cell density. The involvement of miR-3099 in the neurodevelopment of DS has not been investigated and potentially responsible for the neurogenic-to-gliogenic shift phenomenon observed in DS brain. To investigate the role of miR-3099 during DS brain development, neural/progenitor cell proliferation and differentiation, we profiled miR-3099 expression level in the Ts1Cje, a mouse model for DS. We analysed the Ts1Cje whole brain at embryonic day (E) 10.5, E14.5 and P1.5, proliferating neurospheres and differentiating neurospheres at 3, 9 and 15 days in vitro (DIV). Expression of miR-3099 in both the developing mouse brain and the differentiating neurosphere was not significantly different between Ts1Cje and wild type controls. In contrast, the expression level of miR-3099 was significantly higher $(p<0.05)$ in proliferating NSPC derived from the Ts1Cje compared to wild-type. Further molecular profiling of NPSC and glial cell markers indicated that the expression of Sox2 $(p<0.01)$ and Gfap $(p<0.05)$ were significantly downregulated in Ts1Cje neurospheres as compared to that of wild type, respectively. While there were no significant differences in Tuj1 and Nestin expression levels between the Ts1Cje and wild type neurospheres, their expression levels were $\sim 3$-fold upregulated and $\sim 2.6$ downregulated Ts1Cje group, respectively. The findings suggest that dysregulation of miR-3099 affects NSPC lineage commitment as indicated by altered postmitotic neuronal cell markers. Further molecular characterisation and gene expression profiling of other neuronal and glial markers will help refine the analysis of gene-gene interactions underlying the neuropathologies of DS.
\end{abstract}

Keywords: miR-3099; Ts1Cje; neurosphere; Down syndrome; microRNA

C2021 by Zainal Abidin et al. for use and distribution in accord with the Creative Commons Attribution (CC BY-NC 4.0) license (https://creativecommons.org/licenses/by-nc/4.0/), which permits unrestricted non-commercial use, distribution, and reproduction in any medium, provided the original author and source are credited.

\subsection{INTRODUCTION}

Down syndrome (DS) is a high prevalence chromosomal disorder with an incidence rate between 1 in 1,000 to 1 in 1,100 live birth worldwide (Organisation, 2019). The incidence rate is higher in pregnant women $>35$ years old and increases with further maternal age advances
(Hultén et al., 2010). DS is the most common cause of intellectual disability (ID), and it accounts for nearly onethird of all diagnosed ID cases worldwide (Mégarbané et al., 2013). DS is caused by an extra copy of the entire or part of human chromosome 21 (HSA21). Approximately $\sim 4 \%$ of DS patients manifest trisomy 21 due to the 
translocation of chromosome 21 to most often an acrocentric chromosome. About $1 \%$ of DS patients are mosaic and exhibit co-existence of somatic cells with normal and trisomy 21 karyotypes (Mutton et al., 1996).

The ID in DS individuals is mainly a consequence of development perturbations caused by the triplication of HSA21 genes (Antonarakis et al., 2020). Several studies on the neocortex, hippocampus and cerebellum of DS newborns, infants and adults demonstrated a size reduction that was correlated with reduced neuronal density (Aylward et al., 1999; Brunamonti et al., 2011; Menghini et al., 2011; Pinter et al., 2001). In addition, decreased gyri formation, abnormal neocortical and hippocampal lamination, and delayed fibre myelination, were also observed among DS individuals (Ábrahám et al., 2012; Wisniewski, 1990). Dendritic abnormalities are the most consistent anatomical correlates of ID (Moser, 1999). It was proposed that neurogenic-togliogenic switch could play a role in dysregulation of neurodevelopment in DS (Lee et al., 2016). It has been postulated that the skewed of neuronal and glia ratio causes a reduction of the neuronal precursor specification (Briggs et al., 2013). Several pathways were aberrant in trisomic lines, subsequently perturbed the transition from neural stem cell, and the formation of mature neuronal structure. One of the pathways involved in the transition of neuronal to glial differentiation is the JAK-STAT signalling pathway (Lee et al., 2016). In DS brains, overstimulation of the JAKSTAT pathway promotes glial differentiation coupled with the transcription of gliogenic genes such as Gfap and $S 100 \beta$. The expression of APP and DYRK1A was elevated in DS, which subsequently downregulated sonic hedgehog $(\mathrm{SHH})$ signalling pathway and led to reduced neurogenesis in the trisomic brain (Stagni et al., 2018). Moreover, the expression of Gfap was higher in DS brain, and it was consistent with the elevated expression of Gfap in DS mouse model (Hewitt et al., 2010; Lockrow et al., 2012).

MiR-3099 is a 22-nt microRNA (miRNA) that regulates neuronal development. Expression of miR-3099 was observed as early as E3.5 blastocyst stage and continue to express throughout the embryonic stage, particularly at the telencephalon region (E9.5 to E11.5) and later throughout the central nervous system (between E13.5E17.5) (Ling et al., 2011). The expression of miR-3099 was also found upregulated for $\sim 2$-fold in P19 cell upon retinoic acid induction (Ling et al., 2011) as well as upregulated 2-3-fold in 46C mouse embryonic stem (mES) cell following neural induction (Abidin et al., 2014). In an overexpression study, the miR-3099 promoted neuronal differentiation in mES cells evidenced by the upregulation of proneural markers such as NeuN, Tuj1, NeuroD1, Sox4, Gat1, vGluT1 and vGluT2, and downregulation of astrogliogenesis markers such as Gfap, S100B and S/c1a3 (Zainal Abidin et al., 2019). Further in vivo study shows that the overexpression of miR-3099 inhibits the expression of Gfap during corticogenesis (Zainal Abidin et al., 2019). The 3'UTR of Gfap was also validated as miR-3099 target via an in vitro luciferase assay (Abidin et al., 2017). Collectively, these findings indicate that miR-3099 play a regulatory role to suppress astrogliogenesis and to promote neurogenesis by targeting Gfap expression during proneural development. Due to the involvement role of miR-3099 in Gfap regulation during neuronal differentiation, we would like to determine the expression of miR-3099 in DS. To achieve this, we employed Ts1Cje as a mouse model for DS.

Ts1Cje, a mouse model for DS carries an extra copy of MMU16 genes spanning from Sod 1 and $M x 1$ (Sago et al., 1998) with several features suggestive of DS such as craniofacial defects, learning and memory impairment and hypoplasia of the hippocampus (Herault et al., 2017; Vacano et al., 2012). The Ts1Cje carries an extra segment of MMU16 which is conserved synteny to HSA21 (Galdzicki et al., 2001; Pletcher et al., 2001). Ts1Cje also demonstrates cognitive and behavioural abnormalities (Sago et al., 1998), that are associated with ID. The reduction of neurogenesis due to the neurogenic-to-gliogenic shift phenomenon was reported in Ts1Cje, in which neural stem/progenitor cells (NSPCs) tend to differentiate into glial cells when comparing to that of wild type (Hewitt et al., 2010). To elucidate the regulatory role of miR-3099 in the early neurodevelopment of Ts1Cje brain, we examined the expression pattern of miR-3099 throughout different development stages of the Ts1Cje whole brain (E10.5, E14.5 and P1.5) and NSPC that cultured as neurospheres. The neurosphere derived from the E15.5 cerebral cortex was differentiated into the neuronal lineage, and the expression of miR-3099 was also determined. For the DS samples with a significant expression level of miR-3099 compared to that of wild type, the gene expression level of selective neural stem cell, neuronal and glial markers were also evaluated.

\subsection{MATERIALS AND METHODS}

\subsection{Experimental animals}

The Ts1Cje and disomic mice were generated by mating Ts1Cje males with C57BL/6 female mice. The mice were supplied with food, and water ad libitum were maintained in a $12 \mathrm{~h}$ light $/ 12 \mathrm{~h}$ dark cycle. Housing and 
procedures were conducted in accordance with ethical permit approval by Universiti Putra Malaysia Institutional Animal Care and Use Committee (IACUC, UPM/IACUC/AUP-R086/2015).

\subsection{Genotyping of Ts1Cje mice}

The mice tails were harvested and lysed in $500 \mu$ l of lysis buffer [0.1 M Tris- $\mathrm{HCl}$ (pH 8.0), $0.2 \mathrm{M} \mathrm{NaCl}, 5 \mathrm{mM}$ EDTA, $0.2 \%$ SDS and $0.1 \mathrm{mg} / \mathrm{ml}$ proteinase $\mathrm{K}]$. The samples were incubated overnight at $56^{\circ} \mathrm{C}$ followed by centrifugation at $13,000 \mathrm{rpm}$ for $10 \mathrm{~min}$. Then, the supernatant was transferred into $500 \mu \mathrm{l}$ of ice-cold isopropanol and left at room temperature for $5 \mathrm{~min}$. The solution was centrifuged at maximum speed for $5 \mathrm{~min}$ to pellet the DNA. The supernatant was discarded, and the DNA pellet was rinsed twice with $70 \%$ ethanol. The sample was centrifuged again at maximum speed for 5 min. Then, the supernatant was discarded, and DNA pellet was dried at $37^{\circ} \mathrm{C}$. A total of $50 \mu \mathrm{DEPC}$-treated water was used to elution buffer and kept at $65^{\circ} \mathrm{C}$ for 15 $\mathrm{min}$. The extracted DNA was stored at $-20^{\circ} \mathrm{C}$ until further analysis.

The mice were genotyped by using multiplex PCR for neomycin (Neo) and glutamate receptor ionotropic, kainite 1 (Grik1) gene. Genotyping was performed by using two sets of primer, one for Neo gene (forward 5' CTCACCTTGCTCCTGCCGAG-3' and reverse $5^{\prime}$ CTGATGCTCTTCGTCCAGATCATC-3') and the other set for Grik1 gene (forward 5'-CCCCTTAGCATAACGACCAG$3^{\prime}$ and reverse 5'-GGCACGAGACAGACAGTGAG-3'). The PCR reactions were set up, containing $20 \mu \mathrm{l}$ of $1 \mathrm{X}$ LC480 Probe Master Mix (Roche Life Science), $0.5 \mu \mathrm{M}$ of primers, 100 ng of DNA, and remaining DEPC-treated water. The PCR reaction was cycled in Eppendorf Mastercycler Gradient PCR machine (Eppendorf) with an initial denaturation set at $95^{\circ} \mathrm{C}$ for $10 \mathrm{~min}$, followed by 30 cycles of $95^{\circ} \mathrm{C}$ for $10 \mathrm{~s}, 60^{\circ} \mathrm{C}$ for $30 \mathrm{~s}$ and $72^{\circ} \mathrm{C}$ for $10 \mathrm{~s}$ with an additional elongation step at $72^{\circ} \mathrm{C}$ for $7 \mathrm{~min}$. Then, the qualitative analysis was performed on electrophoresed DNA bands in 1-2\% (w/v) agarose gel stained with ethidium bromide.

The Ts1Cje mouse model was generated during Sod1 gene targeting by homologous recombination using a targeting vector containing the neomycin resistance gene (Huang et al., 1997) Neo was used as a positive selection. Grik1 on chromosome 16 was used for background control. Qualitative PCR analysis yielded a specific $176 \mathrm{bp}$ fragment of amplified Neo gene and a 333 bp fragment of Grik1 gene in Ts1Cje, whereas only PCR fragment from Grik1 gene in the wild type mice (Supplementary Figure).

\subsection{Generation of neurosphere cultures derived from E15.5 mouse cerebral cortex}

Cerebral cortices were harvested from the E15.5 mouse embryo. The dissected tissue was placed in Neurobasal medium (Gibco) supplemented with $1 \%(\mathrm{v} / \mathrm{v})$ penicillinstreptomycin $(10,000 \mathrm{U} / \mathrm{ml})$ (Gibco). The cerebral cortex tissues were then transferred into $0.05 \%$ trypsin (Gibco) to dissociate into a single-cell suspension by gentle mechanical pipetting. The single cells were cultured into a growth medium for 5-7 days. The growth medium consists of Neurobasal medium, 1X B-27 supplement (Gibco), $20 \mathrm{ng} / \mathrm{ml}$ epidermal growth factor (EGF) (ThermoFisher Scientific), $20 \mathrm{ng} / \mathrm{ml}$ fibroblast growth factor (FGF) (ThermoFisher Scientific), 1\% GlutaMAX (Gibco), 2 mM L-glutamine (Gibco) and 1\% penicillinstreptomycin.

\subsection{Differentiation of neurosphere}

The neurospheres were dissociated into the single-cell format with $0.05 \%$ trypsin, followed by centrifuge at 800 $\mathrm{rpm}$ for $5 \mathrm{~min}$. The cells were seeded approximately $5 \mathrm{x}$ $10^{4} \mathrm{cell} / \mathrm{ml}$ in the poly-L-lysine-laminin coated 6 -well plate for 3,9 , and 15 days in vitro (DIV) supplemented with the neurodifferentiation media (Neurobasal medium, 1X B-27, 1\% foetal bovine serum (FBS) (Gibco)), 1\% GlutaMAX, 2 mM L-glutamine and 1\% penicillin-streptomycin.

\subsection{RNA extraction from whole-brain tissue}

The total RNA was extracted from whole-brain tissues (E10.5, E14.5 and P1.5), neurospheres and differentiating cells at 3,9 and 15 DIV using TRIzol reagent (Invitrogen) according to the manufacturer's instructions. In brief, the whole brain was homogenised in $1 \mathrm{ml}$ of TRIzol reagent. While for neurospheres and differentiating cells, the media was discarded and resuspended with $1 \mathrm{ml}$ of TRIzol. The sample was then incubated for $5 \mathrm{~min}$ at room temperature to permit complete dissociation of the nucleoprotein complex. Subsequently, $200 \mu \mathrm{l}$ of chloroform was added and incubated for $3 \mathrm{~min}$ at room temperature. Then, the homogenised sample was centrifuged at $12,000 \times$ g for $15 \mathrm{~min}$ at $4^{\circ} \mathrm{C}$. The homogenised sample was separated into three layers, with the lower layer is a red phenolchloroform phase, interphase and upper layer a colourless aqueous phase. The upper layer containing RNAs was transferred into $500 \mu \mathrm{l}$ of $100 \%$ isopropanol and incubated at room temperature for $10 \mathrm{~min}$. The mixture was centrifuged at $12,000 \times \mathrm{g}$ for $10 \mathrm{~min}$ at $4^{\circ} \mathrm{C}$, and the supernatant was discarded, leaving only the RNA pellet. The RNA pellet was then washed with $1 \mathrm{ml}$ of $75 \%$ ethanol and centrifuged at 7,500 $\times \mathrm{g}$ for $5 \mathrm{~min}$ at $4^{\circ} \mathrm{C}$. The supernatant was discarded, and the RNA pellet 
was air-dried for 5-10 min. The RNA pellet was resuspended in $30 \mu \mathrm{I}$ DEPC-treated water and incubated at $60^{\circ} \mathrm{C}$ for $15 \mathrm{~min}$. The RNA was stored at $-80^{\circ} \mathrm{C}$ until further analysis.

\subsection{Stem-loop reverse transcription}

A total of $1.5 \mu \mathrm{g}$ of RNA was synthesised by using Superscript ${ }^{\mathrm{TM}}$ IV Reverse Transcriptase kit (Invitrogen) and $0.1 \mu \mathrm{M}$ of stem-loop primer (5'GTTGGCTCT GGTAGGATG CCGCTCTCA GGGCAT CCTACCAGA GCCAAACTC CCCA'3). The manufacturer's protocol was modified slightly by adding the stem-loop primer after the denaturation step at $65^{\circ} \mathrm{C}$ for $5 \mathrm{~min}$, before incubation on ice for $2 \mathrm{~min}$. The cDNA synthesis was then performed at $16^{\circ} \mathrm{C}$ for $30 \mathrm{~min}$ followed by 60 cycles of $20^{\circ} \mathrm{C}$ for $30 \mathrm{sec}, 42^{\circ} \mathrm{C}$ for $30 \mathrm{sec}$ and $50^{\circ} \mathrm{C}$ for $1 \mathrm{sec}$. A final incubation at $75^{\circ} \mathrm{C}$ for 15 min was performed to inactivate the reverse transcriptase.

\subsection{Pulsed stem-loop-quantitative polymerase chain reaction}

The pre-PCR was performed in $20 \mu$ l of a total reaction containing $0.01 \mathrm{X}$ of CDNA, 1X LC480 Probe Master (Roche), and 1.0 $\mu \mathrm{M}$ of miR-3099 primer and universal reverse primer. The pre-PCR was carried out at $95^{\circ} \mathrm{C}$ for $10 \mathrm{~min}, 55^{\circ} \mathrm{C}$ for $2 \mathrm{~min}$ and another $2 \mathrm{~min}$ at $75^{\circ} \mathrm{C}$ and followed by 14 additional cycles of $95^{\circ} \mathrm{C}$ for $15 \mathrm{sec}$ and $60^{\circ} \mathrm{C}$ for $4 \mathrm{~min}$. Upon pre-PCR, the expression of $m i R$ -
3099 gene was determined by using $1 \mu \mathrm{l}$ of pre-PCR product, 1X LC480 Probe Master, $0.1 \mu \mathrm{M}$ of UPL Probe \#21 (Roche), $1.0 \mu \mathrm{M}$ of forward and universal reverse primer in $10 \mu$ lof total reaction. The qPCR cycle began with an initial denaturation $\left(95^{\circ} \mathrm{C}\right.$ for $\left.10 \mathrm{~min}\right)$ and 45 cycles at $95^{\circ} \mathrm{C}$ for $10 \mathrm{sec}, 60^{\circ} \mathrm{C}$ for $30 \mathrm{sec}$ and $72^{\circ} \mathrm{C}$ for 10 sec. The final step was performed at $40^{\circ} \mathrm{C}$ for $1 \mathrm{sec}$.

While for selected genes qPCR analysis, the samples were prepared in 96-well plates with $10 \mu \mathrm{l}$ per reaction. The reaction consists of 1 X LC480 SYBR Green I Master (Roche), $1.0 \mu \mathrm{M}$ of forward and reverse primers (Table 1). The $q P C R$ analysis was performed with an initial denaturation $\left(95^{\circ} \mathrm{C}\right.$ for $\left.10 \mathrm{~min}\right)$ and $45 \mathrm{cycles}$ of $95^{\circ} \mathrm{C}$ for $10 \mathrm{sec}, 60^{\circ} \mathrm{C}$ for $30 \mathrm{sec}$ and $72^{\circ} \mathrm{C}$ for $10 \mathrm{sec}$, followed by $40^{\circ} \mathrm{C}$ for $1 \mathrm{sec}$. The amplification signals were acquired during the elongation step and recorded by using LightCycler ${ }^{\circledast} 480$ Software version 1.5 . The crossing point $(\mathrm{Cp})$ from each signal was calculated based on the Second Derivative Maximum method (Luu-The et al., 2005).

For miR-3099 expression analysis, a minimum 4-data point standard curve was constructed using serially diluted pooled cDNAs for each primer set used in qPCR in each run. The standard curve was used to determine the PCR efficiency and reproducibility of each PCR

Table 1: List of primer and their properties

\begin{tabular}{|c|c|c|c|c|c|}
\hline \multicolumn{2}{|c|}{ Genes } & Sequence $\left(5^{\prime} \rightarrow 3^{\prime}\right)$ & GC\% & $\operatorname{Tm}\left({ }^{\circ} \mathrm{C}\right)$ & Amplicon Size (bp) \\
\hline \multirow{2}{*}{ Sox2 } & Forward & CGCCCAGTA GACTGCAC A & 61 & \multirow{2}{*}{60} & \multirow{2}{*}{95} \\
\hline & Reverse & СCCTCACAT GTGCGACAG & 61 & & \\
\hline \multirow{2}{*}{ Nestin } & Reverse & TCCCTTAGTCTGGAAGTGGCTA & 50 & \multirow{2}{*}{60} & \multirow{2}{*}{68} \\
\hline & Forward & GGTGTCTGCAAGCGAGAGTT & 55 & & \\
\hline \multirow{2}{*}{ Tuj1 } & Forward & GCGCATCAGCGTATACTACAA & 48 & \multirow{2}{*}{60} & \multirow{2}{*}{85} \\
\hline & Reverse & CATGGTTCCAGGTTCCAAGT & 50 & & \\
\hline \multirow{2}{*}{ Gfap } & Forward & CGCCACCTACAGGAAATTG & 53 & \multirow{2}{*}{60} & \multirow{2}{*}{76} \\
\hline & Reverse & CTGGAGGTTGGAGAAAGTCTGT & 50 & & \\
\hline miR-3099 & Forward & CGCGTAGGC TAGAGAGAG GT & 60 & $c 0$ & $C_{5}$ \\
\hline \multicolumn{2}{|c|}{ Universal reverse primer } & GTAGGATGC CGCTCTCAG G & 63 & 00 & כ0 \\
\hline
\end{tabular}

system. The $U 6$ was used to normalise the quantitative analysis. The normalisation against the housekeeping gene was based on a method as previously described (Ling et al., 2009). While for selected genes, the qPCR data were analysed by using delta-delta $\mathrm{Ct}$ value. Two different genes, Psmb2 and Pgk1 were used to normalise against the gene expression of selected genes.

\subsection{Statistical analysis}

Two-way ANOVA analysis was used to compare the miR3099 expression levels between wild type and Ts1Cje groups, followed by Tukey's test. The size analysis and gene expression study of the neurosphere between wild type and Ts1Cje were compared using Student's t-test. Statistical analyses were performed using GraphPad Prism 7 software. Differences between wild type and 
Ts1Cje groups were considered significant at ${ }^{*} p<0.05$, $* * p<0.01$ and $* * * p<0.001$.

\subsection{RESULTS}

The expression of miR-3099 was examined at different time points of the developing mouse brain (Figure 1). As compared to the E10.5 brain, expression of miR-3099 was elevated in the E14.5 and P1 brains for both genotypes. The miR-3099 expression level was comparable for both genotypes between E14.5 and P1.5 brains without any statistical differences. In both groups, compared to neurospheres, the miR-3099 level was highest at DIV 9 than DIV 3 or DIV 15 (Figure 2). For the wild type group, miR-3099 expression was elevated in differentiating cells at all the three selected timepoints as compared to the proliferating NPSC (Figure 2). For the Ts1Cje group, the expression level of miR-3099 was similar for both the proliferating NPSC and the differentiating cell of DIV 3.

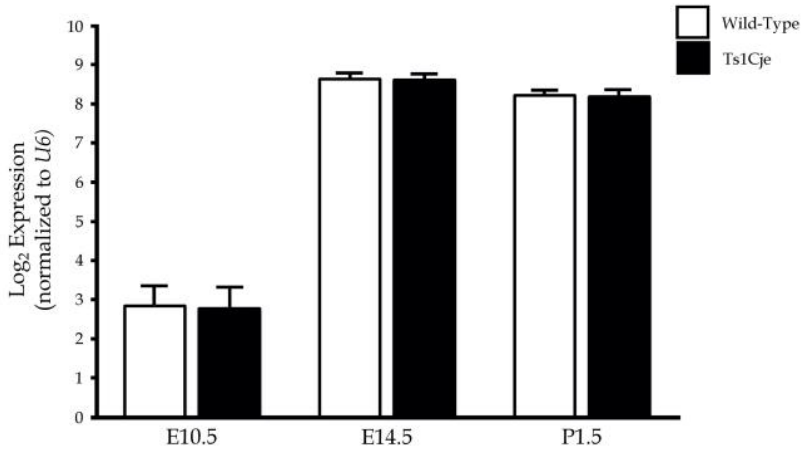

Figure 1: Expression of miR-3099 in Ts1Cje mouse brain development. The stem-loop RT-qPCR analysis was performed on E10.5, E14.5 and P1.5 whole brain (where $n=$ 4). The values were presented as mean \pm SEM. The statistical analysis was performed by using two-way ANOVA followed by Tukey's test.

While there was no significant difference of miR-3099 expression in differentiating cells for both genotypes, it is interesting to note that the expression was upregulated $\sim 4$-fold $(p=0.0448)$ in the Ts1Cje neurospheres when compared with that of wild type. In addition, the size of the Ts1Cje neurosphere (as a measurement of the diameter) $(189.60 \pm 13.349 \mu \mathrm{m})$ was significantly smaller $(p=0.000364)$ as compared to that of wild type $(340.11 \pm 10.276 \mu \mathrm{m})$ (Figure 3). The expression profile of the selected genes (neural stem cell, neuronal and glial markers) in neurospheres (proliferating NSPC) was further compared for both genotypes (Figure 4). The expression of Tuj1 was $\sim 3$-fold higher while Nestin expression was $\sim 2.6$-fold lower in
Ts1Cje neurospheres, but not statistical significance when compared to wild type neurospheres. The expression of Gfap and Sox2 were significantly downregulated for $\sim 2$-fold $(p=0.0113)$ and $\sim 5$-fold $(p=0.00589)$ in Ts1Cje neurospheres as compared to that of wild type, respectively. The results indicate that the upregulation of miR-3099 in the Ts1Cje neurosphere has elevated neuronal marker expression (Tuj1) and suppressed the glial marker expression, Gfap.

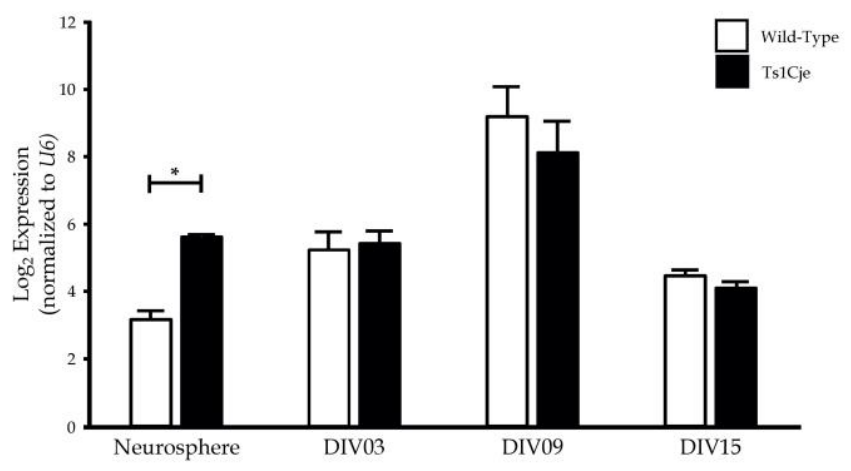

Figure 2: Expression of $m i R-3099$ in neurosphere and differentiating neurosphere. Stem-loop RT-qPCR analysis of miR-3099 in neurosphere (where $\mathrm{n}=6$ ) and differentiating neurosphere at DIV 03, 09 and 15 , where $n=4$. The mean \pm SEM is presented in the bar graph. The statistical analysis was performed by using two-way ANOVA followed by Tukey's test. The asterisk $(*)$ denotes statistical significance at $p<0.05$.

\subsection{DISCUSSION}

No differences in miR-3099 expression were observed in multiple stages of brain development between Ts1Cje and wild type. The expression of miR-3099 in whole brain has a similar pattern in Ts1Cje and wild type, potentially due to the cell heterogeneity that could diluted expression of miR-3099. Throughout the brain development, miR-3099 was expressed at restricted brain regions such as cortical plate, piriform cortex and lower level in the hippocampal formation (Ling et al., 2011). Therefore, spatiotemporal or cell-specific expression profiling using single-cell (sc) RNAseq, immunostaining, flow cytometry or microfluidic technologies would yield a better transcriptomic landscape of miR-3099 during neurodevelopment of Ts1Cje mouse.

The expression of miR-3099 was significantly upregulated in Ts1Cje neurosphere when compared to wild type, but not during the differentiation stages of the neurosphere. The neurosphere is heterogeneous, containing proliferative NPSCs, postmitotic neurones as well as glial cells. Based on findings, both Sox2 (stem cell 

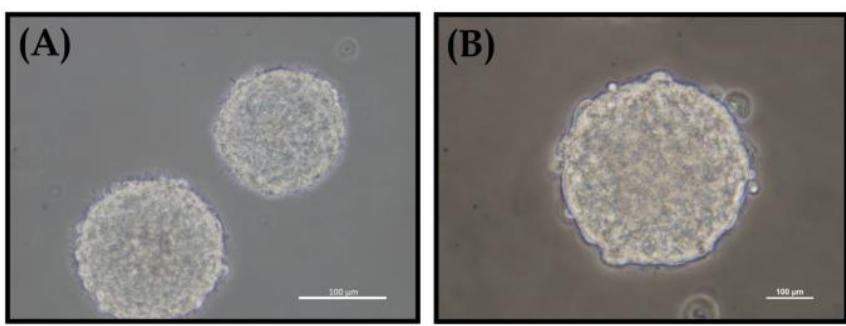

(C)

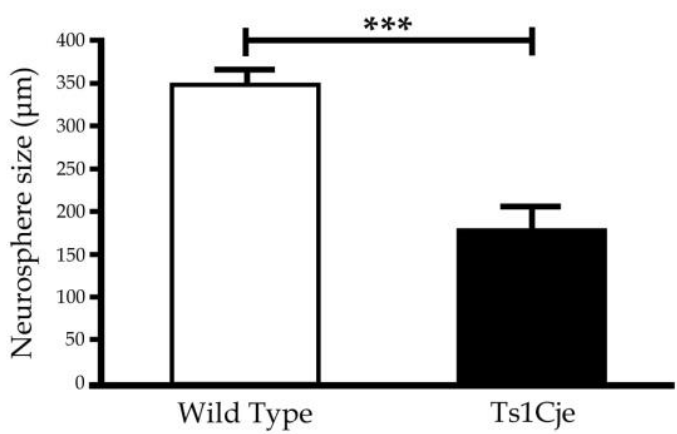

Figure 3: Reduction in size of Ts1Cje-derived neurosphere. Bright-field image of neurosphere derived from E15.5 of (A) wild type and (B) Ts1Cje. Scale bars, $100 \mu \mathrm{m}$. (C) Quantitative analysis of the mean size of neurospheres derived from wild type and Ts1Cje. The mean size of neurospheres derived from Ts1Cje was significantly smaller than wild type (where $n=10$ neurospheres). Error bars show mean \pm SEM, the asterisk $\left({ }^{* *}\right)$ denotes statistical significance at $p<0.001$ based on TTest.
(A)

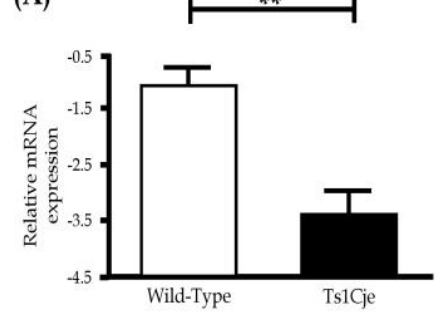

(B)

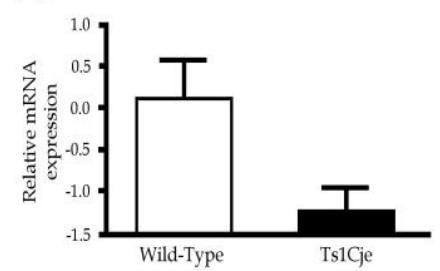

(C)

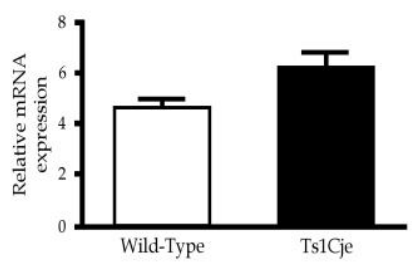

(D)

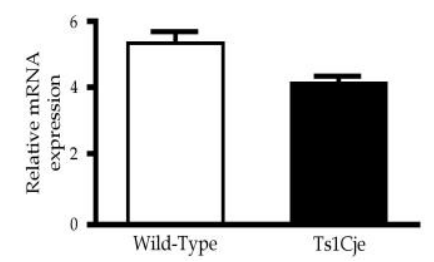

Figure 4: Expression profile of selected genes between Ts1Cje and wild type. The genes were selected based on different markers of neural differentiation, such as (A) stem cell marker, Sox2, (B) neural progenitor marker, Nestin, (C) immature neurone marker, Tuj1 and (D) astrocytes marker, Gfap. Values are presented as mean \pm SEM. Statistical analysis was performed using T-Test. The asterisk denotes significant differences between Ts1Cje and wild type at $p<0.05^{*}$ and $p<0.01 * *, n=3$ biological replicates. marker) and Gfap (astrocytic marker) were significantly downregulated in the Ts1Cje neurosphere, which was in line with our previous study (Zainal Abidin et al., 2019), where the upregulation of miR-3099 in transgenic mouse embryonic stem cell led to a lower expression of Sox2 and Gfap. The Sox 2 has been proposed to be part of the GFAP positive 'glial' population residing in the subependymal region as well as at the base of the granule cell layer of the subventricular zone (Doetsch et al., 1999; Doetsch, 2003; Ferri et al., 2004). It is reported that the miR-3099 was negatively regulating Gfap; hence, by suppressing the expression of Gfap (Abidin et al., 2017; Zainal Abidin et al., 2019), it may indirectly reduce the Sox 2 expression in the neurosphere. The Sox 2 has a critical role in maintaining the pluripotency of the stem cell. Nonetheless, the deficiency of Sox 2 could negatively affect neurosphere formation (Ferri et al., 2004). In DS brain, $\mathrm{SOX2}^{+}$and $\mathrm{GFAP}^{+}$cells were decreased in both the outer subventricular zone (oSVZ) and intermediate zone (IZ) (Baburamani et al., 2020), further affirming the role of Sox2/Gfap in neurogenesis or maintenance of the NSPC pool. While we do not have evidence that indicates miR-3099 direct involvement in Sox2/Gfap regulation in Ts1Cje neurospheres, it is tempting to correlate the miR-3099 upregulation in DS to increased cell cycle exit leading to reduced maintenance of NSPC cell pool. The notion is further corroborated with the well-documented smaller Ts1Cje neurosphere compared to the control $(\underline{H}$. C. Lee et al., 2019; Moldrich et al., 2009; Seth et al., 2020) as the consequences of impaired neurogenesis.

In DS, impairment of neurogenesis is caused by the reduction of the pool size of NSPC and the increased propensity of NSPC to acquire an astrocytic phenotype. A previous study has demonstrated that the number of neurones was reduced by approximately $56 \%$, whereas the number of astrocytes was increased by $6 \%$ in Ts1Cje differentiating neurosphere (Hewitt et al., 2010). Similar findings also reported that DS induced pluripotent stem cell (iPSC)-derived NPC under spontaneous differentiation condition might exhibit a higher percentage of astrocytes ( $78 \%$ ) as compared to control ( $60 \%$ ) (Chen et al., 2014). In this study, the expression of Gfap was downregulated, while Tuj1 was upregulated (even though no significant difference) in proliferating Ts1Cje neurosphere. While our results may suggest early-stage accelerated cell commitment, our findings do not explain how this could lead to the neurogenic-togliogenic shift seen in DS models (Hewitt et al., 2010; Reiche et al., 2019; Zdaniuk et al., 2011). One explanation for the reduced propensity of DS NSPCs to acquire neuronal cell phenotype is the upregulation of 
JAK-STAT and NOTCH signalling pathways in DS that work hand-in-hand to promote astrogliogenesis (Lee et al., 2016; Yusof et al., 2019). These signalling pathways are enhanced by both $A P P$ and DYRK1A that interfere with fate specification, thereby suppressing neurogenesis in the DS brain (Stagni et al., 2018).

A previous study found a miR-3099 homologue in the human genome known as mds21 (Genbank Accession ID: MK521584), which shared $100 \%$ and $64 \%$ identity with miR-3099 seed region and sequence, respectively (Zainal Abidin et al., 2019). This gene was found in low abundance in datasets generated from the human brain, prostate tumour tissue and human embryonic stem cell (Cloonan et al., 2011; Ren et al., 2012; Sherwood et al., 2011). Furthermore, mds21 was expressed in several human cell lines ranging from human cancers, mesenchymal stem cells, amniotic fluid and neuroblast. Interestingly, $m d s 21$ was originated from the sense strand of exon 42 of the BRWD1 gene in HSA21. This gene is involved in chromatin remodelling associated with the SWI/SNF protein complex (Bakshi et al., 2010; Huang et al., 2003). However, mds21 requires further characterisation to elucidate its role in brain development and neural differentiation. Understanding the role and expression pattern of mds 21 could potentially be a molecular therapeutic strategy or marker for DS. Nevertheless, in therapeutic strategy development, it is advisable to not targeting only a single miRNA. Complex regulatory networking involving miRNA-mRNA-protein interactions is not based on a one-to-one relationship but a cluster of miRNAs that synergistically regulate the targeted gene. Another important requirement is a delivery system to target a specific organ at the right time point. The expression of miRNA has dynamic changes through development. The most important in developing a miRNA-targeting strategy is understanding the selectivity, redundancy and specificity of the delivery approach. These prospects of miRNA as a therapeutic target remain promising.

\subsection{CONCLUSIONS}

In summary, we have analysed the expression of miR3099 in the developing Ts1Cje mouse brain, proliferating and differentiating neurosphere. MiR-3099 is known to be important in modulating and regulating neuro-differentiation and suppressing astrogliogenesis. However, this study has demonstrated that the miR3099 expression profile was similar for wild-type and Ts1Cje brains but not the neurosphere. The upregulation of miR-3099 in the Ts1Cje neurosphere coincides with the downregulation of Sox2, Gfap and Nestin, and upregulation of Tuj1. Our findings suggest that upregulation of miR-3099 is associated with an early defect in NPSCs maintenance, potentially via direct/indirect regulation of Sox2/Gfap-mediated pathway. In addition, the upregulation of miR-3099 could be a compensatory mechanism to balance neuronal and astrocyte cell lineage due to the chromosomal abnormalities of Ts1Cje.

Supplementary Materials: Supplementary figure is available online at https://doi.org/10.31117/neuroscirn.v4i1.62.

Acknowledgements: This work was supported by funding from the MOHE Fundamental Research Grant Scheme (FRGS/1/2012/SKK01/UPM/02/3) awarded to KHL and MOSTI Sciencefund (02-01-04-SF2336) awarded to PSC. SZA and HCL were supported by MyBrain15 postgraduate scholarship programme by the Ministry of Higher Education (MoHE), Malaysia.

Author Contributions: SZA and $\mathrm{KHL}$ conceived and designed the experiments; SZA and HCL performed the experiments; SZA and KHL analysed the data; KHL and PSC contributed reagents, materials or analysis tools; SZA wrote the paper; SZA, PSC, SA, NN and KHL developed the paper structure and arguments; SZA and KHL critical revisions and approval of the final version.

Conflicts of Interest: The authors declare no conflict of interest.

\section{References}

Abidin, S. Z., Abbaspourbabaei, M., Ntimi, C. M., Siew, W. H., Cheah, P. S., Rosli, R., Nordin, N., \& Ling, K. H. (2014). MIR-3099 is overexpressed in differentiating $46 \mathrm{c}$ mouse embryonic stem cells upon neural induction. Malaysian Journal of Medical Sciences, 21, 26-32.

Abidin, S. Z., Leong, J.-W., Mahmoudi, M., Nordin, N., Abdullah, S., Cheah, P.-S., \& Ling, K.-H. (2017). In Silico Prediction and Validation of Gfap as an miR-3099 Target in Mouse Brain. Neuroscience Bulletin, 33(4), 373-382. https://doi.org/10.1007/s12264-017-0143-0

Ábrahám, H., Vincze, A., Veszprémi, B., Kravják, A., Gömöri, É., Kovács, G. G., \& Seress, L. (2012). Impaired myelination of the human hippocampal formation in Down syndrome. International Journal of Developmental Neuroscience, 30(2), 147158. https://doi.org/10.1016/j.ijdevneu.2011.11.005

Antonarakis, S. E., Skotko, B. G., Rafii, M. S., Strydom, A., Pape, S. E., Bianchi, D. W., Sherman, S. L., \& Reeves, R. H. (2020). 
Down syndrome. Nature Reviews Disease Primers, 6(1), 1-20. https://doi.org/10.1038/s41572-019-0143-7

Aylward, E. H., Li, Q., Honeycutt, N. A., Warren, A. C., Pulsifer, M. B., Barta, P. E., Chan, M. D., Smith, P. D., Jerram, M., \& Pearlson, G. D. (1999). MRI volumes of the hippocampus and amygdala in adults with Down's syndrome with and without dementia. American Journal of Psychiatry, 156(4), 564-568. https://doi.org/10.1176/ajp.156.4.564

Baburamani, A. A., Vontell, R. T., Uus, A., Pietsch, M., Patkee, P. A., Wyatt-Ashmead, J., Chin-Smith, E. C., Supramaniam, V. G., Donald Tournier, J., Deprez, M., \& Rutherford, M. A. (2020). Assessment of radial glia in the frontal lobe of fetuses with down syndrome. Acta Neuropathologica Communications, 8(1), 141. https://doi.org/10.1186/s40478-020-01015-3

Bakshi, R., Hassan, M. Q., Pratap, J., Lian, J. B., Montecino, M. A., van Wijnen, A. J., Stein, J. L., Imbalzano, A. N., \& Stein, G. S. (2010). The human SWI/SNF complex associates with RUNX1 to control transcription of hematopoietic target genes. Journal of Cellular Physiology, 225(2), 569-576. https://doi.org/10.1002/jcp.22240

Briggs, J. A., Sun, J., Shepherd, J., Ovchinnikov, D. A., Chung, T. L., Nayler, S. P., Kao, L. P., Morrow, C. A., Thakar, N. Y., Soo, S. Y., Peura, T., Grimmond, S., \& Wolvetang, E. J. (2013). Integration-free induced pluripotent stem cells model genetic and neural developmental features of down syndrome etiology. Stem Cells, 31(3), 467-478. https://doi.org/10.1002/stem.1297

Brunamonti, E., Pani, P., Papazachariadis, O., Onorati, P., Albertini, G., \& Ferraina, S. (2011). Cognitive control of movement in down syndrome. Research in Developmental Disabilities, 32(5), 1792-1797. https://doi.org/10.1016/i.ridd.2011.03.008

Chen, C., Jiang, P., Xue, H., Peterson, S. E., Tran, H. T., McCann, A. E., Parast, M. M., Li, S., Pleasure, D. E., Laurent, L. C., Loring, J. F., Liu, Y., \& Deng, W. (2014). Role of astroglia in down's syndrome revealed by patient-derived human-induced pluripotent stem cells. Nature Communications, 5, 4430. https://doi.org/10.1038/ncomms5430

Cloonan, N., Wani, S., Xu, Q., Gu, J., Lea, K., Heater, S., Barbacioru, C., Steptoe, A. L., Martin, H. C., Nourbakhsh, E., Krishnan, K., Gardiner, B., Wang, X., Nones, K., Steen, J. A., Matigian, N. A., Wood, D. L., Kassahn, K. S., Waddell, N., ... Grimmond, S. M. (2011). MicroRNAs and their isomiRs function cooperatively to target common biological pathways. Genome Biology, 12(12), R126. https://doi.org/10.1186/gb-2011-12-12-r126

Doetsch, F., Caille, I., Lim, D. A., Garcia-Verdugo, J. M., \& Alvarez-Buylla, A. (1999). Subventricular zone astrocytes are neural stem cells in the adult mammalian brain. Cell, 97(6), 703-716. https://doi.org/10.1016/S0092-8674(00)80783-7

Doetsch, Fiona. (2003). The glial identity of neural stem cells. Nature Neuroscience, 6(11), 1127-1134. https://doi.org/10.1038/nn1144

Ferri, A. L. M., Cavallaro, M., Braida, D., Di Cristofano, A., Canta, A., Vezzani, A., Ottolenghi, S., Pandolfi, P. P., Sala, M., DeBiasi, S., \& Nicolis, S. K. (2004). Sox2 deficiency causes neurodegeneration and impaired neurogenesis in the adult mouse brain. Development, 131(15), 3805-3819. https://doi.org/10.1242/dev.01204

Galdzicki, Z., Siarey, R., Pearce, R., Stoll, J., \& Rapoport, S. I. (2001). On the cause of mental retardation in Down syndrome: Extrapolation from full and segmental trisomy 16 mouse models. Brain Research Reviews, 35(2), 115-145. https://doi.org/10.1016/S0926-6410(00)00074-4

Herault, Y., Delabar, J. M., Fisher, E. M. C., Tybulewicz, V. L. J., Yu, E., \& Brault, V. (2017). Rodent models in Down syndrome research: Impact and future opportunities. DMM Disease Models and Mechanisms, 10(10), 1165-1186. https://doi.org/10.1242/dmm.029728

Hewitt, C.A., Ling, K.-H., Merson, T. D., Simpson, K. M., Ritchie, M. E., King, S. L., Pritchard, M. A., Smyth, G. K., Thomas, T., Scott, H. S., \& Voss, A. K. (2010). Gene network disruptions and neurogenesis defects in the adult Ts1Cje mouse model of down syndrome. PLoS ONE, 5(7), e11561. https://doi.org/10.1371/journal.pone.0011561

Huang, H., Rambaldi, I., Daniels, E., \& Featherstone, M. (2003). Expression of theWdr9 gene and protein products during mouse development. Developmental Dynamics, 227(4), 608-614. https://doi.org/10.1002/dvdy.10344

Huang, T. T., Yasunami, M., Carlson, E. J., Gillespie, A. M., Reaume, A. G., Hoffman, E. K., Chan, H. P., Scott, R. W., \& Epstein, C. J. (1997). Superoxide-mediated cytotoxicity in superoxide dismutatse-deficient fetal fibroblasts. Archives of Biochemistry and Biophysics, 344(2), 424-432. https://doi.org/10.1006/abbi.1997.0237

Hultén, M. A., Patel, S., Jonasson, J., \& Iwarsson, E. (2010). On the origin of the maternal age effect in trisomy 21 Down syndrome: The oocyte mosaicism selection model. Reproduction, 139(1), 1-9. https://doi.org/10.1530/REP-09-0088

Lee, H.-C., Tan, K.-L., Cheah, P.-S., \& Ling, K.-H. (2016). Potential Role of JAK-STAT Signaling Pathway in the Neurogenic-toGliogenic Shift in Down Syndrome Brain. Neural Plasticity, 2016, 7434191. https://doi.org/10.1155/2016/7434191

Lee, H. C., Md Yusof, H. H., Leong, M. P. Y., Zainal Abidin, S., Seth, E. A., Hewitt, C. A., Vidyadaran, S., Nordin, N., Scott, H. S., Cheah, P. S., \& Ling, K. H. (2019). Gene and protein expression profiles of JAK-STAT signalling pathway in the developing brain of the Ts1Cje down syndrome mouse model. International Journal of Neuroscience, 129(9), 871-881. https://doi.org/10.1080/00207454.2019.1580280

Ling, K.-H., Brautigan, P. J., Hahn, C. N., Daish, T., Rayner, J. R., Cheah, P., Raison, J. M., Piltz, S., Mann, J. R., Mattiske, D. M., Thomas, P. Q., Adelson, D. L., \& Scott, H. S. (2011). Deep sequencing analysis of the developing mouse brain reveals a novel microRNA. BMC Genomics, 12, 176. https://doi.org/10.1186/1471-2164-12-176

Ling, K. H., Hewitt, C. A., Beissbarth, T., Hyde, L., Banerjee, K., Cheah, P. S., Cannon, P. Z., Hahn, C. N., Thomas, P. Q., Smyth, G. K., Tan, S. S., Thomas, T., \& Scott, H. S. (2009). Molecular networks involved in mouse cerebral corticogenesis and spatio-temporal regulation of Sox 4 and Sox11 novel antisense transcripts revealed by transcriptome profiling. Genome 
Biology, 10(10), R104. https://doi.org/10.1186/gb-2009-10-10-r104

Lockrow, J. P., Fortress, A. M., \& Granholm, A. C. E. (2012). Age-related neurodegeneration and memory loss in down syndrome. Current Gerontology and Geriatrics Research, 2012, 463909. https://doi.org/10.1155/2012/463909

Luu-The, V., Paquet, N., Calvo, E., \& Cumps, J. (2005). Improved real-time RT-PCR method for high-throughput measurements using second derivative calculation and double correction. BioTechniques, 38(2), 287-293. https://doi.org/10.2144/05382RR05

Mégarbané, A., Noguier, F., Stora, S., Manchon, L., Mircher, C., Bruno, R., Dorison, N., Pierrat, F., Rethoré, M. O., Trentin, B., Ravel, A., Morent, M., Lefranc, G., \& Piquemal, D. (2013). The intellectual disability of trisomy 21: Differences in gene expression in a case series of patients with lower and higher IQ. European Journal of Human Genetics, 21(11), 12531259. https://doi.org/10.1038/ejhg.2013.24

Menghini, D., Costanzo, F., \& Vicari, S. (2011). Relationship between brain and cognitive processes in down syndrome. Behavior Genetics, 41(3), 381-393. https://doi.org/10.1007/s10519-011-9448-3

Moldrich, R. X., Dauphinot, L., Laffaire, J., Vitalis, T., Hérault, Y., Beart, P. M., Rossier, J., Vivien, D., Gehrig, C., Antonarakis, S. E., Lyle, R., \& Potier, M. C. (2009). Proliferation deficits and gene expression dysregulation in Down's syndrome (Ts1Cje) neural progenitor cells cultured from neurospheres. Journal of Neuroscience Research, 87(14), 3143-3152. https://doi.org/10.1002/jnr.22131

Moser, H. W. (1999). Dendritic anomalies in disorders associated with mental retardation. Developmental Neuropsychology, 16(3), 369-371. https://doi.org/10.1207/S15326942DN1603 18

Mutton, D., Alberman, E., \& Hook, E. B. (1996). Cytogenetic and epidemiological findings in Down syndrome, England and Wales 1989 to 1993. Journal of Medical Genetics, 33(5), 387-394. https://doi.org/10.1136/img.33.5.387

Organisation, W. H. (2019). No Title. Gene and Human Disease: Down Syndrome. https://www.who.int/genomics/public/geneticdiseases/en/index1.html

Pinter, J. D., Eliez, S., Schmitt, J. E., Capone, G. T., \& Reiss, A. L. (2001). Neuroanatomy of Down's syndrome: A high-resolution MRI study. American Journal of Psychiatry, 158(10), 1659-1665. https://doi.org/10.1176/appi.ajp.158.10.1659

Pletcher, M. T., Wiltshire, T., Cabin, D. E., Villanueva, M., \& Reeves, R. H. (2001). Use of comparative physical and sequence mapping to annotate mouse chromosome 16 and human chromosome 21. Genomics, 74(1), 45-54. https://doi.org/10.1006/geno.2001.6533

Reiche, L., Küry, P., \& Göttle, P. (2019). Aberrant Oligodendrogenesis in Down Syndrome: Shift in Gliogenesis? Cells, 8(12), 1591. https://doi.org/10.3390/cells8121591

Ren, S., Peng, Z., Mao, J.-H., Yu, Y., Yin, C., Gao, X., Cui, Z., Zhang, J., Yi, K., Xu, W., Chen, C., Wang, F., Guo, X., Lu, J., Yang, J., Wei, M., Tian, Z., Guan, Y., Tang, L., ... Sun, Y. (2012). RNA-seq analysis of prostate cancer in the Chinese population identifies recurrent gene fusions, cancer-associated long noncoding RNAs and aberrant alternative splicings. Cell Research, 22(5), 806-821. https://doi.org/10.1038/cr.2012.30

Sago, H., Carlson, E. J., Smith, D. J., Kilbridge, J., Rubin, E. M., Mobley, W. C., Epstein, C. J., \& Huang, T. T. (1998). Ts1Cje, a partial trisomy 16 mouse model for Down syndrome, exhibits learning and behavioral abnormalities. Proceedings of the National Academy of Sciences of the United States of America, 95(11), 6256-6261. https://doi.org/10.1073/pnas.95.11.6256

Seth, E. A., Lee, H.-C., Yusof, H. H. bin M., Nordin, N., Cheah, Y. K., Ho, E. T. W., Ling, K.-H., \& Cheah, P.-S. (2020). Phenotype microarrays reveal metabolic dysregulations of neurospheres derived from embryonic Ts1Cje mouse model of Down syndrome. PLOS ONE, 15(7), e0236826. https://doi.org/10.1371/journal.pone.0236826

Sherwood, R. I., Maehr, R., Mazzoni, E. O., \& Melton, D. A. (2011). Wnt signaling specifies and patterns intestinal endoderm. Mechanisms of Development, 128(7-10), 387-400. https://doi.org/10.1016/J.MOD.2011.07.005

Stagni, F., Giacomini, A., Emili, M., Guidi, S., \& Bartesaghi, R. (2018). Neurogenesis impairment: An early developmental defect in Down syndrome. Free Radical Biology and Medicine, 114, 15-32. https://doi.org/10.1016/i.freeradbiomed.2017.07.026

Vacano, G. N., Duval, N., \& Patterson, D. (2012). The use of mouse models for understanding the biology of down syndrome and aging. Current Gerontology and Geriatrics Research, 2012, 717315. https://doi.org/10.1155/2012/717315

Wisniewski, K. E. (1990). Down syndrome children often have brain with maturation delay, retardation of growth, and cortical dysgenesis. American Journal of Medical Genetics, 7(SUPPL. 7), 274-281. https://doi.org/10.1002/ajmg.1320370755

Yusof, H. H., Lee, H. C., Seth, E. A., Wu, X., Hewitt, C. A., Scott, H. S., Cheah, P. S., Li, Y. M., Chau, D. M., \& Ling, K. H. (2019). Expression Profiling of Notch Signalling Pathway and Gamma-Secretase Activity in the Brain of Ts1Cje Mouse Model of Down Syndrome. Journal of Molecular Neuroscience, 67(4), 632-642. https://doi.org/10.1007/s12031-019-01275-2

Zainal Abidin, S., Fam, S. Z., Chong, C. E., Abdullah, S., Cheah, P. S., Nordin, N., \& Ling, K. H. (2019). miR-3099 promotes neurogenesis and inhibits astrogliogenesis during murine neural development. Gene, 697, 201-212. https://doi.org/10.1016/i.gene.2019.02.014

Zdaniuk, G., Wierzba-Bobrowicz, T., Szpak, G. M., \& Stępień, T. (2011). Astroglia disturbances during development of the central nervous system in fetuses with Down's syndrome. Folia Neuropathologica, 49(2), 109-114. 